\title{
THE DISSOLUTION AND DIFFUSION OF FUROSEMIDE ON SELF- NANOEMULSIFYING DRUG DELIVERY SYSTEM (SNEDDS)
}

\begin{abstract}
Iis Wahyuningsih ${ }^{1 *}$, Sugiyanto², Ag. Yuswanto ${ }^{3}$, Ronny Martien ${ }^{4}$
1Faculty of Pharmacy, Ahmad

Dahlan University,

Yogyakarta, 55164,

Indonesia,

2Lab. of Pharmacology \&

Toxicology, Faculty of

Pharmacy, Universitas

Gadjah Mada, Yogyakarta,

55281, Indonesia

${ }^{3}$ Dept. of Pharmacy, Faculty

of Medicine, Atma Jaya

University, Jakarta, Indonesia

${ }^{4}$ Lab. of Pharmaceutical

Technology, Faculty of

Pharmacy, Universitas

Gadjah Mada, Yogyakarta,

55281, Indonesia

ABSTRACT

Furosemide a diuretic exhibits low solubility in water and low bioavailability. The purpose of this study was to determine the effect SNEDDS formation to dissolution and diffusion of furosemide. SNEDDS was made with a mixture of $66 \%$ tween 80 , $26 \%$ propylene glycol, $8 \%$ oleic acid and furosemide $40 \mathrm{mg} / \mathrm{mL}$. Test for SNEDDS dissolution of the capsules was developed using USP dissolution apparatus I and compared to market products, furosemide suspenssion and furosemide powder. The medium consists of $900 \mathrm{~mL}$ of Artificial Gastric Fluid (AGF), phosphate buffer $\mathrm{pH} 5.8$ at $37 \pm 0.5^{\circ} \mathrm{C}$ and stirred with a speed of $100 \mathrm{rpm}$. Diffusion test of SNEDDS furosemide was conducted by using reversed rat intestinal bowel and compared to furosemide suspension and furosemide solution. The SNEDDS formulation could enhance the dissolution and diffusion of furosemide compared to the non-SNEDDS formulation.
\end{abstract}

Submitted: 02-02-2017

Revised: 05-03-2017

Accepted: $10-04-2017$

${ }^{*}$ Corresponding author

Iis Wahyuningsih

Email:

avinagil@gmail.com

Keywords: furosemide, SNEDDS, dissolution, diffusion

\section{INTRODUCTION}

Furosemide is a loop diuretic which is used in the treatment of edema, congestive heart failure and hypertension (Berkó et al., 2002). Furosemide has poor and variable bioavailability due to poor solubility in gastric fluid $(5-20 \mu \mathrm{g} / \mathrm{mL})$ (Lindenberg et al., 2004). Furosemide is a drug belonging to Biopharmaceutical Class System (BCS) class IV (Custodio et al., 2008), with the low dissolution rate. This low dissolution rate represents the first factor responsible for poor bioavailability. A technological approaches are able to improve this property, can represent an important starting point for enhancing drug pharmaceutical use.

Furosemide dosage forms development is being undertaken to increase solubility which eventually is expected to improve bioavailability. One such development is to create SNEDDS. SNEDDS are isotropic mixtures of oil, surfactant, cosurfactant and drugs that form an oil nanoemulsion in water when added to the water phase under slowly stirring (Nazzal et al., 2002). These systems spontaneously form an nanoemulsion when exposed to Gastro Intestinal Tract (GIT) liquids to form oil droplet in water with the size in the range of 20-200nm (Porter et al., 2008). SNEDDS able to improve the bioavailability of poorly soluble drugs by improving dissolution and permeability through biological membranes due to the present of lipid and surfactant (O'Driscoll, 2002). Small globule size of SNEEDS also provides a large surface area interface for drug release and absorption (Wang et al., 2009). Other advantags are of high stability, entrapment efficiency of $100 \%$, a potential decrease in the dose and dose frequency (due to increase bioavailability), the potential to provide protection for the drug against degradation in the environment of the GIT and ease of manufacturing and scale-up (Kale and Patravale, 2008; Shaji and Jadhav, 2010). SNEDDS is preferred because small 
total volume are allowed being filled into hard or soft gelatin capsules. SNEDDS also contain surfactants which are in lower amount than self-micro emulsifying drug delivery system (SMEDDS), thereby reducing the risk of surfactants to cause stomach irritation and other toxicity (Gupta et al., 2011).

In previous studies had been obtained the optimum formula SNEDDS furosemide (Wahyuningsih et al., 2016) but has yet been determined the impact of the dissolution and diffusion of furosemide. The purpose of this study was to determine the effect of SNEDDS against dissolution and diffusion of furosemide.

\section{MATERIAL AND METHODS Preparation of SNEDDS}

SNEDDS was made with a mixture of $66 \%$ tween $80,26 \%$ propilene glycol, $8 \%$ oleic acid and furosemide $40 \mathrm{mg} / \mathrm{mL}$. Preparation of SNEDDS furosemide formula was carried out by mixing tween 80 and Propylene Glycol (PG) in vortex mixer for $1 \mathrm{~min}$, then added oleic acid and vortex again for $2.5 \mathrm{~min}$.

\section{Physical characteristics}

The SNEDDS of furosemide was characterized for transmittance, emusification time and particle size. The $\%$ transmittance of SNEDDS furosemide was measured at $630 \mathrm{~nm}$ using UV-Vis spectrophotometer against distilled water as the blank. Emusification time for SNEDDS furosemide was performed using USP dissolution apparatus II by agitation at $100 \mathrm{rpm}$. One hundred $\mu \mathrm{L}$ of SNEDDS furosemide was added of water $(500 \mathrm{~mL})$ at temperature $37^{\circ} \mathrm{C}$. The mean droplet size was determined by using Particle Size Analyzer (Horiba Scientific SZ-100).

\section{Dissolution test}

SNEDDS furosemide was filled into soft gelatin capsules and stored at room temperature for 24h (Basalious et al., 2010). Test for furosemide release of the capsules was developed using USP dissolution apparatus I /basket and compared to market products, furosemide suspenssion and furosemide powder. The medium consists of $900 \mathrm{~mL}$ of AGF, phosphate buffer $\mathrm{pH} 5.8$ at $37 \pm 0.5^{\circ} \mathrm{C}$ and stirred with a speed of $100 \mathrm{rpm}$. At regular intervals, $5 \mathrm{~mL}$ samples were taken and replaced with an equal volume of fresh medium to maintain the volume. Sample was then filtered using a membrane filter and the drug concentration was determined by mean of UV spectrophotometer.

\section{Diffusion test in vitro}

Diffusion test was performed using reverse intestine taken from Wistar male rats that were fasted for $20-24 \mathrm{~h}$ prior to the test. Mice were sacrificed using chloroform and dissected the stomach along the center line of the body and the intestinal was separated. The intestine was taken $15 \mathrm{~cm}$ from the pylorus. The intestinal length of $20 \mathrm{~cm}$, was taken then the intestine divided into 2 equal lengths approximately $10 \mathrm{~cm}$ each. Intestinal contents was purged with $\mathrm{NaCl} 0.9 \% \mathrm{w} / \mathrm{v}$ and then gut was reversed with a rod diameter of $2 \mathrm{~mm}$. The intestine was attached to the cannula tube of Crane \& Wilson then was tied to the aeration cannula with an effective length of $7 \mathrm{~cm}$. The study protocol had been approved by the Ethics Committee of Gadjah Mada University No. 426/KEC-LPPT/II/2016.

Each of furosemide and furosemide SNEDDS solution that has been prepared was used as a mucosal fluid and placed in a tube test as much as $75 \mathrm{~mL}$. The tube was is then placed into a water bath with the temperature of $37^{\circ} \mathrm{C}$. The serosal fluid with $\mathrm{pH} 6.2$ phosphate buffer solution was incorporated into the intestinal sac mounted on a cannula, was then inserted into the tube which has been conditioned in a waterbath. The system was aerated with oxygen with the velocities of approximately 100bubbles/min. During the experiments must be confirmed that the entire portion of the intestine has been submerged in mucosal fluids.

One $\mathrm{mL}$ aliquot was taken at 20,40,60 and $80 \mathrm{~min}$. Each of the sample was placed into a test tube and then was added $2 \mathrm{~mL}$ of zinc sulfate $5 \% \mathrm{w} / \mathrm{v}$ and $2 \mathrm{~mL}$ of $0.3 \mathrm{~N}$ barium hydroxide and was centrifuged for $25 \mathrm{~min}$. The supernatant was separated and the furosemide contains was measured by spectrophotometry method. 


\section{RESULT AND DISSCUSION}

Some physical properties of the furosemide SNEDDS obtained (Table I).

Table I. Physical properties of the furosemide SNEDDS

\begin{tabular}{lll}
\hline Parameters & Average & SE \\
\hline Transmittan (\%) & 95.773 & 0.0315 \\
Emusification time (s) & 28.5 & 1.5 \\
Particle size (nm) & 88.9 & 4.9 \\
\hline
\end{tabular}

The transparancy of the SNEDDS was expressed in percent transmittance. This is one of the characteristics of SNEDDS to be determined because of the effect on particle size. Observations clarity visually represent qualitative parameters spontaneity of dispersion (Xia et al., 2010), while the transmittance is close to $100 \%$ indicates that SNEDDS produce a clear and transparent dispersion with a droplet size estimated at the nanometer (Bali et al., 2010). When the SNEDDS formula was mix with water produced clear water-emulsion with the transmittance of more than 95\%, indicating that the size of the droplets produced has met the criteria of nanoemulsion.

Emulsification time test was performed to determine how fast formula SNEDDS form an emulsion (Zhao, 2015). The test results showed emulsification time less than $1 \mathrm{~min}$. The SNEDDS formula capable of forming the emulsion after direct contact with gastric fluid, to produce an emulsion system is quite clear (Makadia et al., 2013).

Determining the size of the droplet is made to ensure that the nanometer-sized emulsion formed. Droplet categorized nanoemulsion if the file size is below $100 \mathrm{~nm}$ (Doh et al., 2013). The results obtained showed that the droplet size was of $88.9 \mathrm{~nm}$.

The release of furosemide from SNEDDS, suspension and other formulation (Figure 1). The SNEDDS showed different dissolution profile when compared with powders, suspensions or tablets on the market, especially at $\mathrm{pH}$ 1.2. In vitro release test was carried out in Artificial Gatro Fluid (AGF) solution $\mathrm{pH} 1.2$ and $\mathrm{pH} 5.8$ phosphate buffer (Figure 1). Drug release at $\mathrm{pH} 5.8$ and at $\mathrm{pH} 1.2$ as shown in the dissolution efficiency (DE) (Table II). At pH 5.8, the drug is released quickly enough and complete in $2 \mathrm{~h}$. The release of furosemide lower at $\mathrm{pH} \mathrm{1.2,} \mathrm{it} \mathrm{is} \mathrm{because}$ furosemide has $\mathrm{pKa} \sim 3.9$. At $\mathrm{pH} 1.2$, furosemide, particularly in the form of molecule whereas at pH 5.8 while keeping in ionized form furosemide is more soluble in water.

Table II. Dissolution efficiency value

\begin{tabular}{lcc}
\hline \multicolumn{1}{c}{ Formulation } & \multicolumn{2}{c}{ DE Value } \\
\cline { 2 - 3 } & AGF & $\begin{array}{c}\text { Buffer } \\
\text { phosphat 5.8 }\end{array}$ \\
\hline $\begin{array}{l}\text { Furosemide } \\
\text { powder }\end{array}$ & $5.37 \pm 0.047$ & $28.04 \pm 0.009$ \\
$\begin{array}{l}\text { Furosemide } \\
\text { SNEDDS }\end{array}$ & $36.46 \pm 0.030 *$ & $40.70 \pm 0.127 *$ \\
$\begin{array}{l}\text { Furosemide } \\
\text { Suspension } \\
\text { Marketed dosage } \\
\text { form }\end{array}$ & $4.55 \pm 0.010$ & $46.44 \pm 0.340$ \\
\hline
\end{tabular}

Specification: *significant difference in all formulations $(\mathrm{p}<0.05)$

At pH 1.2 media, Dissolution Efficiency (DE) furosemide produced most of SNEDDS furosemide, at the $\mathrm{pH} 5.8$ furosemide was not significantly different between the SNEDDS and the suspension. The DE SNEDDS furosemide was largest because in part is affected by SNEDDS components, namely oleic acid, tween 80 and PG. Oleic acid was chosen as the oil phase in the formulation SNEDDS for self-emulsifying capabilities of its high-capacity and large drug dissolution (Miryala and Kurakula, 2013).

PG can increase solubility of a hydrophilic surfactant such as tween 80 and the solubility of the drug in the oil base (Amrutkar et al., 2014). The results are consistent with the results of research conducted by Swaroopa et al., (2014), oleic acid formulation, water, tween 80 and PG can increase the release of the drug than the formula contains oleic acid, water, Cremophor RH 40 and ethanol.

From (Figure 2) that the number of furosemide that diffuses from SNEDDS furosemide greater than furosemide suspension and furosemide solution. The same thing can also (Table III) parameters of diffusion permeability and flux SNEDDS furosemide have the greatest value. Increased furosemide 


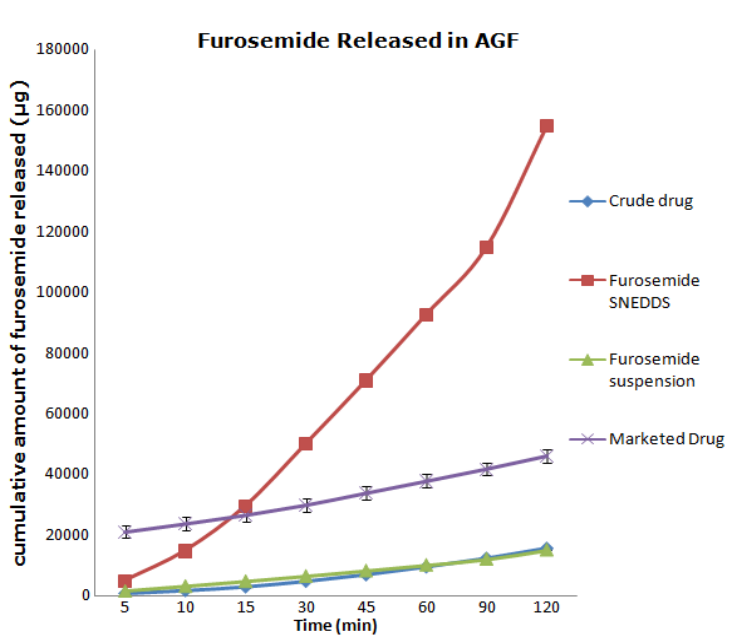

(A)

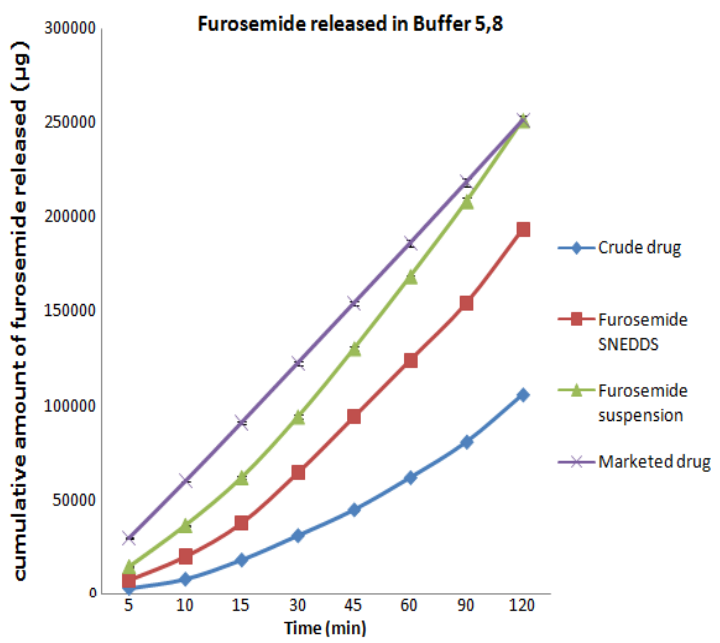

(B)

Figure 1. The profile of furosemide release in(A) AGF(pH1.2) and in (B) phosphate buffer (pH 5.8) at $37^{\circ} \mathrm{C} \pm 0.5$ of furosemide powder, furosemide SNEDDS and furosemide suspension. Data represent the average of five independent determinations \pm SE and furosemide suspension. Data represent the average of five independent determinations $\pm \mathrm{SE}$.

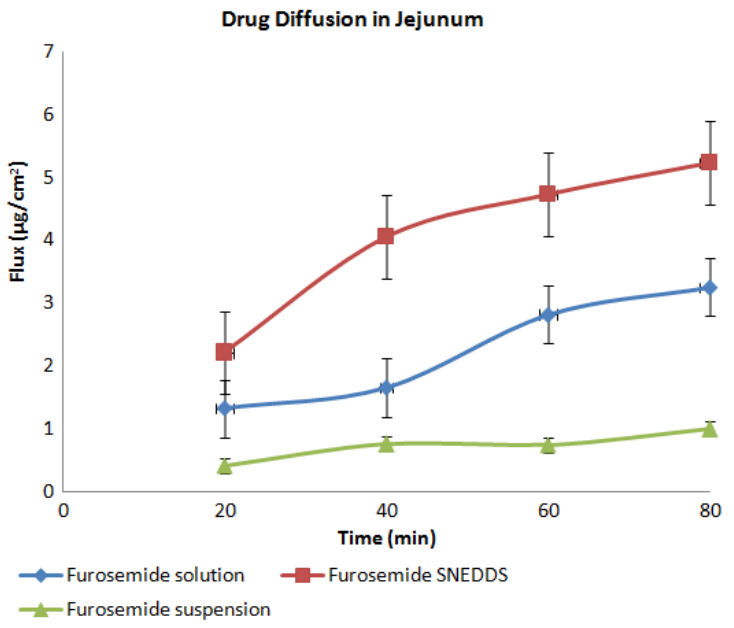

(A)

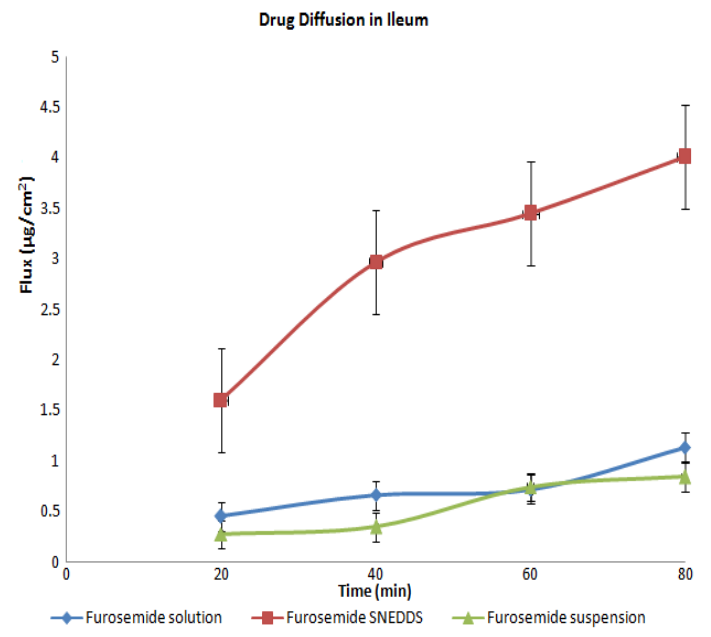

(B)

Figure 2. In vitro drug diffusion of crude drug, furosemide SNEDDS and furosemide suspension in (A) jejunum (B) ileum. Data represent the average of three independent determinations $\pm \mathrm{SE}$

diffusion due to the influence of each of the excipients used in SNEDDS which are oleic acid, tween 80 and PG.

Oleic acid can act as an enhancer with localizes hydrophobic drug to the multilamellar lipid membrane (Yu et al., 2003). Oleic acid, the class of fatty acids, is included enhancers to increase the rate of diffusion by increasing membrane fluidity (Hadgraft and Walters, 1993).
The absorption of furosemide was inhibited significantly by P-gp, whereas Tween 80 showed to inhibit P-gp pump. As a result, It will inhibit furosemide efflux, which the concentration of furosemide inside cells is remain high (Al-Mohizea, 2010). Tween 80 has also the ability to inhibit P-gp of intestines and has been widely used to increase the permeability of various drugs in in vitro study (Prabhakar et al., 2013). Surfactants can increase 
Table III. Diffusion parameters of solution, suspension, SNEDDS furosemide in jejunum and ileum.

\begin{tabular}{ccccc}
\hline \multirow{2}{*}{ Formulation } & \multicolumn{2}{c}{ Jejunum } & \multicolumn{2}{c}{ Ileum } \\
\cline { 2 - 5 }$\left(\mathrm{min}^{-1} \cdot \mathrm{cm}^{-2}\right)$ & $\left(\mu \mathrm{g} \cdot \mathrm{min}^{-1} \cdot \mathrm{cm}^{-2}\right)$ & $\begin{array}{c}\text { Permeability } \\
\left(\mathrm{min}^{-1} \cdot \mathrm{cm}^{-2}\right)\end{array}$ & $\begin{array}{c}\text { Flux } \\
\left(\mu \mathrm{g} \cdot \mathrm{min}^{-1} \cdot \mathrm{cm}^{-2}\right)\end{array}$ \\
\hline $\begin{array}{c}\text { Furosemide } \\
\text { solution }\end{array}$ & $1.74 \times 10^{-4} \pm 5.28 \times 10^{-5}$ & $3.47 \times 10^{-2} \pm 1.05 \times 10^{-2}$ & $5.27 \times 10^{-5} \pm 1.44 \times 10^{-5}$ & $1.05 \times 10^{-2} \pm 2.87 \times 10^{-3}$ \\
$\begin{array}{c}\text { Furosemide } \\
\text { SNEDDS }\end{array}$ & $2.44 \times 10^{-4} \pm 5.20 \times 10^{-5}$ & $4.87 \times 10^{-2} \pm 1.04 \times 10^{-2}$ & $1.92 \times 10^{-4} \pm 6.00 \times 10^{-5}$ & $3.84 \times 10^{-2} \pm 1.20 \times 10^{-2}$ \\
$\begin{array}{c}\text { Furosemide } \\
\text { suspension }\end{array}$ & $9.63 \times 10^{-5} \pm 1.46 \times 10^{-5}$ & $1.93 \times 10^{-2} \pm 2.93 \times 10^{-3}$ & $1.05 \times 10^{-4} \pm 1.57 \times 10^{-5}$ & $2.11 \times 10^{-2} \pm 3.14 \times 10^{-3}$ \\
\hline
\end{tabular}

fluidity of the intestinal membrane and open the tight junctions which resulted in an increase of membrane permeability (Mohsin et al., 2012; Porter et al., 2008; Rajesh et al., 2010). On the other hand, tween 80 can also act as an enhancer to improve membrane permeation (Acharya et al., 2013).

PG is one of the compounds to facilitate drug transportation to the polar lipids of membrane (Trommer and Neubert, 2006). It will increase the penetration of drugs across the membrane. PG is as cosolvent to produce a saturated solution to maximize the drug thermodynamic activity. PG can be used as a penetration enhancer at a concentration of $1 \%$ to $10 \%$ (Williams and Barry, 2004).

The finding of this study consistent with that of Acharya et al., (2013) which proved that the combination among oleic acid, tween 80 and PG can increase the diffusion of carbamazepine.

\section{CONCLUSION}

SNEDDS formulation can enhance the dissolution and diffusion of furosemide.

\section{ACKNOWLEDGEMENTS}

This study was supported by Ahmad Dahlan University on Hibah Bersaing 2016 with No : PHB-33/LPP_UAD/III/2016.

\section{REFERENCES}

Acharya, S.P., Pundarikakshudu, K., Panchal, A., Lalwani, A., 2013. Preparation and evaluation of transnasal microemulsion of carbamazepine. Asian J. Pharm. Sci. 8, 64-70. doi:10.1016/j.ajps.2013.07.008

Al-Mohizea, A.M., 2010. Influence of intestinal efflux pumps on the absorption and transport of furosemide. Saudi Pharm. J. SPJ 18, 97-101. doi:10.1016/j.jsps.2010.02.005

Amrutkar, C., Salunkhe, K., Chaudhari, S., 2014. Study on Self Nano Emulsifying Drug Delivery System of Poorly Water Soluble Drug Rosuvastatin Calcium. World J. Pharm. Res. 3, 2137-2151.

Bali, V., Ali, M., Ali, J., 2010. Study of surfactant combinations and development of a novel nanoemulsion for minimising variations in bioavailability of ezetimibe. Colloids Surf. B Biointerfaces 76, 410-420. doi:10.1016/j.colsurfb.2009.11.021

Basalious, E.B., Shawky, N., Badr-Eldin, S.M., 2010. SNEDDS containing bioenhancers for improvement of dissolution and oral absorption of lacidipine. I: development and optimization. Int. J. Pharm. 391, 203211. doi:10.1016/j.ijpharm.2010.03.008

Berkó, S., Regdon Jr., G., Ducza, E., Falkay, G., Erős, I., 2002. In vitro and in vivo study in rats of rectal suppositories containing furosemide. Eur. J. Pharm. Biopharm. 53, 311-315. doi:10.1016/S09396411(02)00005-X

Custodio, J.M., Wu, C.Y., Benet, L.Z., 2008. Predicting drug disposition, absorption elimination btransporter interplay and the role of food on drug absorption. Adv. Drug Deliv. Rev. 60, 717-733. doi:10.1016/j.addr.2007.08.043 
Doh, H.J., Jung, Y., Balakrishnan, P., Cho, H.J., Kim, D.D., 2013. A novel lipid nanoemulsion system for improved permeation of granisetron. Colloids Surf. B Biointerfaces 101, 475-480. doi:10.1016/j.colsurfb.2012.07.019

Gupta, S., Chavhan, S., Sawant, K.K., 2011. Self-nanoemulsifying drug delivery system for adefovir dipivoxil: Design, characterization, in vitro and ex vivo evaluation. Colloids Surf. Physicochem. Eng. Asp. 392, 145-155. doi:10.1016/j.colsurfa.2011.09.048

Hadgraft, J., Walters, K.A., 1993. Pharmaceutical Skin Penetration Enhancement.

Kale, A.A., Patravale, V.B., 2008. Design and evaluation of self-emulsifying drug delivery systems (SEDDS) of nimodipine. AAPS PharmSciTech 9, 191196. doi:10.1208/s12249-008-9037-9

Lindenberg, M., Kopp, S., Dressman, J.B., 2004. Classification of orally administered drugs on the World Health Organization Model list of Essential Medicines according to the biopharmaceutics classification system. Eur. J. Pharm. Biopharm. Off. J. Arbeitsgemeinschaft Für Pharm. Verfahrenstechnik EV 58, 265-278. doi:10.1016/j.ejpb.2004.03.001

Makadia, M.H.A., Bhatt, M.A.Y., Parmar, M.R.B., Paun, M.J.S., Tank, D.H.M., 2013. Self-nano Emulsifying Drug Delivery System (SNEDDS): Future Aspects. Int. J. Technol. 3, 21-27.

Miryala, V., Kurakula, M., 2013. Self-Nano Emulsifying Drug Delivery System (SNEDDS) for Oral Delivery of Atorvastatin- Formulation and Bioavailability Studies. J. Drug Deliv. Ther. 3, 131-142.

Mohsin, K., Shahba, A.A., Alanazi, F.K., 2012. Lipid Based Self Emulsifying Formulations for Poorly Water Soluble Drugs-An Excellent Opportunity. ResearchGate 46, 88-96.

Nazzal, S., Smalyukh, I.I., Lavrentovich, O.D., Khan, M.A., 2002. Preparation and in vitro characterization of a eutectic based semisolid self-nanoemulsified drug delivery system (SNEDDS) of ubiquinone: mechanism and progress of emulsion formation. Int. J. Pharm. 235, 247-265.

O’Driscoll, C.M., 2002. Lipid-based formulations for intestinal lymphatic delivery. Eur. J. Pharm. Sci. Off. J. Eur. Fed. Pharm. Sci. 15, 405-415.

Porter, C.J.H., Pouton, C.W., Cuine, J.F., Charman, W.N., 2008. Enhancing intestinal drug solubilisation using lipidbased delivery systems. Adv. Drug Deliv. Rev. 60, 673-691. doi:10.1016/j.addr.2007.10.014

Prabhakar, K., Afzal, S.M., Surender, G., Kishan, V., 2013. Tween 80 containing lipid nanoemulsions for delivery of indinavir to brain. Acta Pharm. Sin. B 3, 345-353. doi:10.1016/j.apsb.2013.08.001

Rajesh, B.., Reddy, T.., Srikanth, G., Mallikarjun, V., Nivethithai, P., 2010. Lipid Based Self-emulsifying Drug Delivery System (SEDDS) for Poorly water-soluble Drugs: A Review. JGlob Pharma Technol 2, 47-55.

Shaji, J., Jadhav, D., 2010. Newer Approches to Self Emulsifying Drug Delivery System. Int. J. Pharm. Pharm. Sci. 2, 37-42.

Swaroopa, A., Aparna, C., Srinivas, P., 2014. Formulation, Evaluation and Characterization of Periodontal Microemulsion Gel. Int. J. Pharm. Sci. Drug Res. 6, 20-25.

Trommer, H., Neubert, R.H.H., 2006. Overcoming the stratum corneum: the modulation of skin penetration. A review. Skin Pharmacol. Physiol. 19, 106121. doi:10.1159/000091978

Wahyuningsih, I., Sugiyanto, Yuswanto, A., Martien, R., 2016, Optimasi dan Karakterisasi Formula SNEDDS Furosemid, Laporan Penelitian.

Wang, L., Dong, J., Chen, J., Eastoe, J., Li, X., 2009. Design and optimization of a new self-nanoemulsifying drug delivery system. J. Colloid Interface Sci. 330, 443448. doi:10.1016/j.jcis.2008.10.077

Williams, A.C., Barry, B.W., 2004. Penetration enhancers. Adv. Drug Deliv. Rev. 56, 603618. doi:10.1016/j.addr.2003.10.025 
Xia, D., Quan, P., Piao, H., Piao, H., Sun, S., Yin, Y., Cui, F., 2010. Preparation of stable nitrendipine nanosuspensions using the precipitation-ultrasonication method for enhancement of dissolution and oral bioavailability. Eur. J. Pharm. Sci. Off. J. Eur. Fed. Pharm. Sci. 40, 325-334. doi:10.1016/j.ejps.2010.04.006

Yu, B., Kim, K.H., So, P.T.C., Blankschtein, D., Langer, R., 2003. Visualization of oleic acid-induced transdermal diffusion pathways using two-photon fluorescence microscopy. J. Invest. Dermatol. 120, 448$455 . \quad$ doi:10.1046/j.15231747.2003.12061.x

Zhao, T., 2015. Self-nanoemulsifying drug delivery systems (SNEDDS) for the oral delivery of lipophilic drugs. University of Trento. 